\title{
KUALITAS SEMEN SAPI PEJANTAN SIMMENTAL DAN LIMOUSIN YANG DIPELIHARA DALAM TIPE KANDANG YANG BERBEDA DI BALAI INSEMINASI BUATAN LEMBANG
}

\author{
Bastiana Elvira Lagu, Endang Pudjihastuti, Umar Paputungan*, Sri Adiani
}

FakultasPeternakan, Universitas Sam Ratulangi Manado 95115

\begin{abstract}
ABSTRAK
Manajemen pemeliharaan sapi pejantan meliputi tipe kandang untuk melindungi sapi terhadap gangguan luar yang merugikan termasuk sengatan matahari, kedinginan, kehujanan, tiupan angin yang kencang dan predator. Tujuan penelitian ini untuk mengevaluasi apakah perbedaan model kandang tunggal pejantan (KT) dan kandang ganda pejantan (KD) mempengaruhi kualitas semen Sapi Pejantan Limousin dan Simmental di Balai Inseminasi Buatan (BIB) Lembang. Data primer dan sekunder reproduksi sapi Pejantan Limousin dan Simmental yang diperoleh dari BIB Lembang, Jawa Barat telah digunakan dalam penelitian ini yang dianalisis dengan metode uji $\mathrm{t}(\mathrm{t}$ test). Hasil penelitian diperoleh bahwa rata-rata volume semen ternak sapi Limousin dan Simmental dalam KT $(9,54 \pm 2,19$ $\mathrm{mL} /$ ejakulasi) telah nyata lebih tinggi $7,67 \%$ dibandingkan dengan semen ternak sapi tersebut dalam KD $(8,86 \pm 1,79$ mL/ejakulasi). Rata-rata persentase motilita spermatozoa semen ternak sapi Limousin dan Simmental dalam KD $(71,00$ $\pm 2,67)$ berbeda tidak nyata dengan ratarata persentase motilitas spermatozoa semen ternak sapit ersebut dalam KT $(70,10 \pm 2,37)$. Rata-rata gerakan massa spermatozoa semen ternak sapi Limousin dan Simmental dalam KT $(1,84 \pm 0,37)$ telah nyata lebih agresif $5,43 \%$ dibandingkan dengan rata-rata gerakan massa spermatozoa semen ternak sapi
\end{abstract}

*Korespondensi (corresponding author):

Email : umarfapet@yahoo.com tersebut dalam $\mathrm{KD}(1,94 \pm 0,24)$. Rata-rata $\mathrm{pH}$ semen ternak sapi Limousin dan Simmental dalam KT $(6,66 \pm 0,11)$ tidak nyata berbeda dengan rata-rata $\mathrm{pH}$ semen ternak sapi tersebut dalam KD (6,64 \pm $0,10)$. Hubungan antara variabel reproduksi pejantan Limousin dan Simmental dalam KT dan KD tidak berkorelasi antara variabel satu dengan variabel lain yang ditunjukkan angka korelasi yang hanya berkisar -0,29 sampai 0,18. Berdasarkan hasil pembahasan dapat disimpulkan bahwa kualitas semen sapi limousin dan Simental yang dipelihara di kandang tunggal lebih baik jika dibanding dengan yang dipelihara di kandang ganda. Hubungan antara variabel reproduksi pejantan Limousin dan Simmental yang dipelihara pada kandang tunggal dan kandang ganda tidak berkorelasi antar variabel satu dengan variabel lain.

Kata Kunci: Tipe Kandang, Kualitas Semen, SapiLimousin, Sapi Simmenta

\section{ABSTRACT}

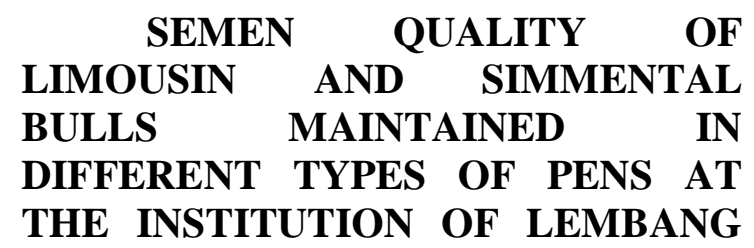

ARTIFICIAL. The intensive maintenance of bulls included animal house and pens protecting animals against sunlight, cool effect, rain, high speed of win and other predators. Objective of this study was to evaluate effects of single bull in a pen (SB) and double bulls in a pen (DB) on semen quality of Limousin and Simmental bulls at 
the Institution of Lembang Artificial Insemination in West Java. Primer and secondary data of both bulls reproduction were used in this study and analyzed by $t$ test method. Results showed that average volume of semen in both bulls of Limousin and Simmental under SB (9.54 \pm 2.19 $\mathrm{mL} /$ ejaculation) was significantly higher of 7.67 percents than those of bulls under DB $(8.86 \pm 1.79 \mathrm{~mL} / \mathrm{ejaculation})$. The average of percentage of spermatozoa motility in both bulls of Limousin and Simmental under DB (71.00 \pm 2.67) was not significantly differ with those of bulls under SB (70.10 \pm 2.37). The average of spermatozoa mass movement in both bulls of Limousin and Simmental under SB (1.84 $\pm 0.37)$ was significantly more aggressive of 5.43 percents than those of bulls under DB (1.94 \pm 0.24$)$. Finally, the average of $\mathrm{pH}$ of semen in both bulls of Limousin and Simmental under SB $(6.66 \pm 0.11)$ was not significantly differ with those of bulls under DB $(6.64 \pm 0.10)$. Correlation between reproduction variables of both Limousinand Simmental bulls in SB and DB was not correlated between one and another variables indicated by correlation values ranging from -0.29 to 0.18 . Based of the result of study can be concluded that semen quality of Limousin and Simental in single pen was better than that in double pens. The correlations among reproductive veriables of Limousin and Simmental in both sigle and double pens had no correlation between one and another variable.

Keyword: Type of Pen, Semen Quality, Simmental Bull, Limousin Bull.

\section{PENDAHULUAN}

Indonesia berada di urutan keempat untuk negara berpopulasi terbesar, setelah Cina, India, Amerika Serikat. Indonesia mempunyai jumlah penduduk di atas 210 juta jiwa jelas yang menyebabkan kebutuhan pangan asal hewani masih sangat tinggi untuk setiap tahunnya. Untuk itu peternakan menjadi komoditi usaha yang baik dan mempunyai peranan yang cukup besar dalam perekonomian nasional (Khairi, 2016). Kandang merupakan salah satu sarana utama yang sangat penting bagi seorang peternak, salah satunya yaitu bagi peternak dalam pemeliharaan ternak. Kandang juga sebagai salah satu faktor lingkungan hidup yang bisa memberikan jaminan hidup yang sehat dan nyaman, sesuai dengan kebutuhan hidup ternak, contohnya ternak ruminansia sapi, kambing, dan domba. Tipe kandang yang digunakan di Balai Inseminasi Buatan Lembang Jawa Barat adalah tipe kandang tunggal dan Ganda (Suryana, 2009). Oleh karena itu komposisi dari kandang harus dapat melindungi dari parasit lain atau gangguan dari luar yang dapat mempengaruhi kesehatan ternak sapi. Bangunan kandang diupayakan untuk dapat melindungi ternak dari gangguan luar yang merugikan. Hal ini dilakukan untuk memperbaiki mutu genetik ternak, menghindari penyebaran penyakit kelamin dan meningkatkan jumlah keturunan dari pejantan unggul (Hafes, 2000). Kandang juga berfungsi untuk melindungi ternak dari perubahan cuaca atau iklim yang 
ekstrem, mencegah serta melindungi ternak dari penyakit, melindungi keamanan ternak dari pencurian, memudahkan pengelolaan ternak dalam proses produksi seperti pemberian pakan, air minum, pengelolaan kompos dan perkawinan guna meningkatkan efesien pengguna tenaga kerja.

Lingkungan seperti suhu dan kelembaban berpengaruh pada aktivitas produksi semen, suhu lingkungan yang tinggi terutama pada musim kemarau mengurangi juga pada lama periode berahi pada sapi betina. Aktivitas birahi terganggu apabila sapi tidak mendapatkan energi yang cukup, sehingga kondisinya menjadi buruk

Kualitas dan kuantitas semen diketahui dengan proses pemeriksaan secara makroskopis dan mikroskopis. Tujuan penelitian ini untuk mengevaluasi apakah perbedaan model kandang tunggal pejantan (KT) dan kandang ganda pejantan (KD) mempengaruhi kualitas semen Sapi Pejantan Limousin dan Simmental di Balai Inseminasi Buatan (BIB) Lembang.

\section{MATERI DAN METODE PENELITIAN}

Penelitian ini dilaksanakan sejak tanggal 18 Desember 2017 sampai dengan 5 Januari 2018, selama 3 minggu, bertempat di Balai Inseminasi Buatan
(BIB) Lembang, Jawa Barat dengan suhu $19^{\circ} \mathrm{C}$. Ternak yang di gunakan yaitu ternak sapi bangsa Limousin dan bangsa Simmental yang berjumlah total 50 ekor dengan masing-masing bangsa sebanyak 25 ekor yang secara keseluruhan diambil semen segar. Adapun peralatan yang akan digunakan dalam penelitian ini adalah Vegina Buatan, Tabung Penampung Yang Berskala, Kandang Jepit, pH Meter, Pipet Ukur, $\mathrm{pH}$ Indicator Paper dan thermos air hangat.

Prosedur peniltian yang dilakukan dengan cara yaitu:

- Pembersihan kandang,

- Memandikan ternak

- Pemberian pakan ternak

- Ternak bangsa Simmental dan Limousin dibawa ke kandang penampungan semen

- Penampungan semen dilakukan dengan mengunakan vagina buatan

- Semen dibawa ke -ruang laboratorium. Pengujian kualitas semen secara makroskopis melalui pengamatan dengan menggunakan daftar tabel untuk menilai gerakan massa dengan menggunakan derajat gerakan massa spermatozoa meliputi sangat baik $(+++)$ terlihat gelombang-gelombang besar, banyak gelap, tebal, dan aktif bagaikan gumpalan awan hitam dekat waktu hujan yang bergerak cepat berpindah-pindah 
tempat; baik (++) bila terlihat gelombanggelombang kecil, jarang, tipis, kurang jelas, dan bergerak lamban; sedang (+) tidak terlihat gelombang melainkan hanya gerakan gerakan individual aktif progresif; dan buruk necrospermia $(0 / \mathrm{N})$ bila hanya sedikit atau tidak ada gerakan individu. Mikroskopis melalui pengamatan dengan menggunakan daftar tabel pengamatan dan mikroskopis (volume, $\mathrm{pH}$, Motilitas spermatozoa, gerakan spermatozoa).

Variabel yang diamati dalam penilitian ini adalah volume semen, $\mathrm{pH}$ semen, motilitas spermatozoa dan gerak spermatozoa.

Analisis data yang yang diterapkan adalah dianalisis secara statistik deskriptif yaitu dengan tabulasi, rata-rata sampel, presentase, standar deviasi, dan dilakukan uji $\mathrm{t}$ dan korelasi antara variabel serta koefisien keragaman (Byrkit, 1987) sebagai berikut:

Standar deviasi $(\mathrm{sd})=\sqrt{\frac{(\mathrm{X}-\overline{\mathrm{X}})^{2}}{\mathrm{n}-1}} ; \quad \overline{\mathrm{X}}=\frac{\sum \mathrm{X}}{\mathrm{n}}$ Koefisien keragaman $(\mathrm{KK})=\frac{\mathrm{sd}}{\overline{\mathrm{x}}} \times 100 \%$

Keterangan :

$\mathrm{X}=$ Variabel yang diamati

$\overline{\mathrm{X}} \quad=$ Rata-rata variabel yang diamati

$\mathrm{n} \quad=$ Jumlah pengamatan variabel

Performan kualitas semen segar dari pejantan sapi pada dua tipe kandang yang berbeda di Balai Insemiansi Buatan (BIB)
Lembang dilakukan melalui análisis varian melalui uji t atau t test (Byrkit, 1987) dengan rumus sebagai berikut:

$$
t=\frac{\overline{\mathrm{x}}_{1}-\overline{\mathrm{x}}_{2}}{\sqrt{\frac{\mathrm{s}_{1}^{2}}{\mathrm{n}_{1}}+\frac{\mathrm{s}_{2}^{2}}{\mathrm{n}_{2}}}}
$$

Keterangan :

$\overline{\mathrm{X}}_{1}=$ Rata-rata nilai kelompok ke-1

$\overline{\mathrm{X}}_{2}=$ Rata-rata nilai kelompok ke-2

$\mathrm{S}_{1}^{2}=$ Varian kelompok ke-1

$\mathrm{S}_{1}^{2}=$ Varian kelompok ke-2

$\mathrm{n}_{1}=$ Banyak subjek kelompok ke-1

\section{HASIL DAN PEMBAHASAN}

Hasil pemeriksaanterhadapveriabel volume semen $(\mathrm{ml}), \mathrm{pH}$ semen, motilitas spermatozoa dan gerakan masa spermatozoa semen segarternaksapi Simmental dan Limousin yang dipelihara pada kandang tunggal dan kandang ganda dapat dilihat pada Tabel 1.

\section{Volume Semen}

Dari hasil pengamatan volume semen ternak sapi Simmental dan Limousin, volume semen berkisar antara 5$12 \mathrm{~mL} /$ ejekulasi dari setiap penampungan. Arifiantini (2012) menyatakan bahwa volume semen sapi merupakan cairan yang diperoleh dalam setiap ejakulat atau banyaknya hasil koleksi yang umumnya berkisar antara 5-8 mL/ejakulat. Semen 
Tabel 1. Rata-rata Volume, pH, Motilitas dan Gerakan Massa Spermatozoa Semen Segar Sapi Simmental dan Limousin dipelihara dalam kandang tunggal dan kandang ganda

\begin{tabular}{lcllll}
\hline Variabel Semen & $\begin{array}{l}\text { Jumlah } \\
\text { Sampel (n) }\end{array}$ & $\begin{array}{l}\text { KandangTunggal } \\
\text { Rata-rata } \pm \text { SD }\end{array}$ & $\begin{array}{l}\text { KK } \\
(\%)\end{array}$ & $\begin{array}{l}\text { Kandang Ganda } \\
\text { Rata-rata } \pm \text { SD }\end{array}$ & $\begin{array}{l}\text { KK } \\
(\%)\end{array}$ \\
\hline Volume (ml) & 50 & $9,54 \pm 2,19^{\mathrm{a}}$ & 22,96 & $8,86 \pm 1,79^{\mathrm{b}}$ & 20,20 \\
$\mathrm{pH}$ & 50 & $6,66 \pm 0,11$ & 1,65 & $6,64 \pm 0,10$ & 1,51 \\
Motilitas (\%) & 50 & $70,10 \pm 2,37$ & 3,38 & $71,00 \pm 2,67$ & 3,76 \\
Gerakan Massa & 50 & $1,84 \pm 0,37^{\mathrm{a}}$ & 20,11 & $1,94 \pm 0,24^{\mathrm{b}}$ & 12,37
\end{tabular}

Keterangan: Superskrip pada baris yang sama menunjukkan berbeda nyata $(\mathrm{P}<0,05)$

bangsa Simmental dan Limousin termasuk volume yang berada pada kisaran normal, sesuai dengan laporan Hartanti et al. (2012) 5-10 mL/ejakulat. Penelitian ini masih dikatakan lebih tinggi jika dibandingkan dengan penelitian Muada et al. (2017) yang menyatakan bahwa volume semen sapi Limousin dan Simmental adalah rata-rata berkisar 7,17 sampai 7,20 mL/ejakulasi.

Berdasarkan hasil penelitian yang disajikan dalam Tabel 1 di atas, terlihat bahwa rata-rata volume semen segar sapi yang dipelihara pada kandang tunggal lebih tinggi yaitu 9,54 $\mathrm{mL}$ dibandingkan dengan rata-rata volume semen sapi yang dipelihara pada kandang ganda, yakni 8,86 mL. Jika dilihat dari koefesien keragaman volume semen segar kedua bangsa ternak sapi Simmental dan Limousin, yaitu antara 20,20 sampai 22,96\%, telah berada pada keragaman yang tinggi. Kurnianto (2010) menyatakan jika koefesien keragaman lebih besar dari $15 \%$ maka dapat dilakukan seleksi.

\section{pH Semen}

Hasil pemeriksaan $\mathrm{pH}$ semen segar ternak sapi Simmental dan Limousin yang dipelihara pada kandang tunggal dan kandang ganda dapat dilihat pada Tabel 1. Berdasarkan hasil penelitian secara mikroskopis semen segar ternak sapi Simmental dan Limousin menunjukkan rata-rata volume semen segar sebanyak 6,66 dengan koefisien keragaman 1,65\% pada ternak sapi yang dipelihara pada kandang tunggal dan sebanyak 6,64 dengan koefesien keragaman $1,51 \%$ pada ternak sapi yang dipelihara pada kandang ganda. Penelitian ini masih sama dengan hasil penelitian Muada et al. (2017) bahwa pH semen ternak sapi Limousin dan Simmental adalah rata-rata berkisar 6,65 sampai 6,66.

Hasil tabulasi dan analisis data semen ternak sapi yang dipelihara pada kandang tunggal dan pada kandang ganda dengan uji t diperoleh nilai $\mathrm{P}=0,1093$ yang menunjukkan nilai $\mathrm{P}>0,05$. Hal ini dapat dikatakan bahwa $\mathrm{pH}$ semen ternak sapi 
Simmental dan Limousin pada kedua tipe kandang adalah berbeda tidak nyata karena nilai perhitungan uji $\mathrm{t}$ dengan hasil $\mathrm{P}=$ 0,1093 adalah lebih besar dari $\mathrm{P}=0,05$ atau $(\mathrm{P}>0,05)$. Kesamaan ini bisa terjadi karena bangsa, berat badan, pakan ternak adalah sama sedangkan perbedaan manajemen kandang tunggal dan kandang ganda tidak dapat memberi efek berbeda pada $\mathrm{pH}$ semen pejantan hasil penampungan (Melita et al., 2014).

Angka pH semen ternak sapi tersebut masih tergolong dalam keadaan normal. Penelitian ini didukung oleh Arifiantini (2012) yang menyatakan bahwa derajat keasaman $(\mathrm{pH})$ semen segar mamalia adalah berkisar antara 6,0 sampai 7,5. Penelitian Hafez (2000) menyatakan bahwa $\mathrm{pH}$ semen untuk ternak ruminansia Kambing atau domba berkisar adalah Peranakan Etawa sekitar 6,8. Hal ini sesuai dengan penilitian Dewi et al. (2012) yang menyatakan bahwa sapi hasil uji $\mathrm{pH}$ pada semen sapi Jawa pada umur yang berbeda menujukan tidak terdapat perbedaan. Berbeda dengan $\mathrm{pH}$ semen kerbau dari hasil penilitian Kiani et al. (2014) menyatakan bahwa $\mathrm{pH}$ semen kerbau kundhi berumur kurang dari 5 tahun akan menghasilkan $\mathrm{pH}$ semen terendah $(6,39 \pm 0,93)$, semen kerbau pada umur $6-8$ dan $\geq 8$ tahun $(6,71 \pm 0,04$ dan $(6,71 \pm 0,01)$.

\section{Motilitas Spermatozoa}

Hasil pengamatan pada motilitas spermatozoa ternak sapi Simmental dan Limousin (Tabel 1), diperoleh hasil berkisar antara 67- 74\% dari setiap penampungan. Motilitas spermatozoa semen dapat nilai setelah dilakukan penampungan semen, kemudian diamati dan dicatat. Hasil penelitian ini menunjukkan hampir sama dengan laporan Turyan (2005) yang melaporkan bahwa sapi Limousin mempunyai rata-rata persentase motilitas spermatozoa adalah $76 \pm 0,05 \%$. Rata-rata motilitas semen ternak sapi ini masih tergolong baik sesuai dengan hasil penelitian Menurut Garner dan Hafez (2000) pada sapi tropis yaitu mortalitas spermatozoa berkisar antara 40 sampai $70 \%$ dan juga Menurut Toelihare (1993) yang menyatakan bahwa motilitas semen segar berkisar 50 sampai $80 \%$. Spermatozoa progessif menghasilkan gerakan massa Spermatozoa, namun tergolong rendah jika dibandingkan dengan hasil penelitian oleh Rahmawati et al. (2015) yang hanya motilitas spermatozoa berkisar 62 sampai 64\%. Namun hasil penelitian ini menunjukkan hasil yang masih lebih rendah jika dibandingkan dengan hasil penelitian oleh Sarastina et al. (2012) dimana motilitas Spermatozoa pada ternak sapi Limousin rata-rata $80,72 \pm 6,34 \%$. Penelitian ini lebih tinggi 
jika dibandingkan dengan pendapat Sugiarto et al. (2014) yang menyatakan bahwa motilitas spermatozoa ternak sapi Limousin adalah rata-rata $58 \pm 2,74 \%$. Selanjutnya menurut Khairi (2016) bahwa motilitas ternak sapi Simmental dengan bobot badan 910-958 kg adalah 48,08\%. Penelitian ini masih dikatakan lebih tinggi jika dibandingkan dengan hasil penelitian Muada et al. (2017) yang menyatakan bahwa motilitas spermatozoa semen ternak sapi Limousin dan Simmental adalah ratarata berkisar 58,80 sampai 59,29\%.

\section{Gerakan Massa Spermatozoa}

Hasil penelitian ini menunjukkan bahwa gerakan massa spermatozoa semen ternak sapi bangsa Simmental dan Limousin berada pada kisaran angka $1,84 \pm 0,37$ sampai $1,94 \pm 0,24$. Penilitan ini hampir sama dengan penilitian Nyuwita $e t$ al. (2015) yang menyatakan bahwa ratarata motilitas massa yang di hasilkan sapi Simmental umur yang berbeda adalah 1,94 $\pm 0,14$. Hal ini menujukan bahwa semen memiliki motilitas yang normal. Hafes (2008) menyatakan bahwa motilitas massa sapi adalah 2+ sampai 3+ seperti pada Tabel 1. Gerakan massa spermatozoa semen diberi angka 1 angka 2 angka 3 dan angka 4 pada gerakan spermatozoa. Angka 1 atau +++ menunjukkan gerakan massa sangat baik; terlihat gelombang- gelombang besar, banyak gelap, tebal, dan aktif bagaikan gumpalan awan hitam dekat waktu hujan yang bergerak cepat berpindah-pindah tempat. Angka 2 atau ++ menunjukkan baik; bila terlihat gelombang-gelombang kecil, jarang, tipis, kurang jelas, dan bergerak lamban. Angka 3 atau + menunjukkan sedang, tidak terlihat gelombang melainkan hanya gerakan gerakan individual aktif progresif. Untuk angka 4 atau $0 / \mathrm{N}$ menunjukkan buruk; necrospermia; bila hanya sedikit atau tidak ada gerakan individu.

Bila gerakan massa spermatozoa semen semakin lemah dengan nilai 3 sampai 4, maka konsentrasi spermatozoa semakin menurun dan semen akan semakin encer begitu pula sebaliknya, bila gerakan massa spermatozoa semen semakin aktif berada pada angka 1 dan 2, maka menunjukkan konsentrasi spermatozoa diharapkan semakin tinggi dan semen semakin kental (Coulter et al., 1997; Dewi et al., 2012; Bhakat et al., 2014). Semakin tinggi gerakan massa spermatozoa semen dapat diartikan semakin tinggi pula konsentrasi. Aerens et al. (2012) dan Ariefin et al. (2013) juga menambahkan bahwa derajat keaktifan gerakan massa spermatozoa semen memiliki korelasi positif terhadap kandungan spermatozoa didalam semen sehingga apabila dalam pengamatan ditemukan semen yang terlalu 
encer maka dapat diduga bahwa semen tersebut memiliki konsentrasi dan gerakan massa spermatozoa semen yang rendah.

Jika dilihat dari koefesien keragaman gerakan massa spermatozoa semen segar kedua bangsa ternak sapi Simmental dan Limousin, yaitu antara 12,37 sampai $20,37 \%$, telah berada pada keragaman yang sedang sampai tinggi. Kurnianto (2010) menyatakan jika koefesien keragaman 10-15\% adalah tergolong sedang dan koefisien keragaman $>15 \%$ dapat dikatakan koefisien keragaman sangat tinggi sehingga perlu dilakukan seleksi terhadap individu dalam suatu populasi.

\section{Korelasi Antar Variabel Reproduksi}

Hasil pengamatan terhadap prediksi hubungan antara variabel reproduksi ternak untuk mengantisipasi dan memprediksi salah satu peran variabel agar mampu meningkatkan peran variabel lain diprediksi dalam bentuk angka korelasi, baik bersifat positif maupun bersifat negatif. Analisis korelasi antara variabel reproduksi ternak sapi Simmental dan Limousin dalam penelitian ini dapat dilihat pada Tabel 2.

\section{Korelasi Antara Volume dengan pH, Motilitas dan Gerakan Massa Spermatozoa}

Berdasarkan hasil ini bahwa angka korelasi antara volume dengan $\mathrm{pH}$ semen ternak sapi (Tabel 2) adalah -0,06 pada ternak sapi yang dipelihara pada kandang tunggal, dan 0,03 pada ternak sapi yang dipelihara pada kandang ganda. Angkaangka korelasi ini menunjukkan bahwa kuantitas variabel volume semen tidak memiliki hubungan untuk mempengaruhi kuantitas variabel $\mathrm{pH}$ semen, sehingga dapat mengindikasikan bahwa kuantitas.

Tabel 2. Korelasi Antara Variabel Reproduksi Pejantan Simmental dan Limousin yang Dipelihara pada Kandang Tunggal dan Kandang Ganda

\begin{tabular}{|c|c|c|c|c|}
\hline Kandang Ganda & Volume (mL) & $\mathrm{pH}$ & $\begin{array}{l}\text { Motilitas } \\
(\%)\end{array}$ & $\begin{array}{l}\text { Gerakan } \\
\text { massa }\end{array}$ \\
\hline Volume (ml) & - & $-0,06$ & 0,03 & $-0,29$ \\
\hline $\mathrm{pH}$ & 0,03 & - & 0,18 & $-0,14$ \\
\hline Motilitas (\%) & $-0,10$ & 0,05 & - & $-0,21$ \\
\hline Gerakan Massa & $-0,22$ & $-0,14$ & $-0,21$ & - \\
\hline
\end{tabular}

Keterangan: Angka-angka korelasi di atas diagonal adalah varibel ternak sapi pada kandang tunggal, angka-angka korelasi di bawah diagonal adalah variable ternak sapi pada kandang ganda. 
Selanjutnya hasil penelitian ini juga menunjukkan bahwa angka korelasi antara volume dengan motilitas spermatozoa semen ternaksapi (Tabel 2) adalah 0,03 pada ternak sapi yang dipelihara pada kandang tunggal dan $-0,10$ pada ternak sapi yang dipelihara pada kandang ganda. Angka-angka korelasi ini menunjukkan bahwa kuantitas variabel volume semen tidak juga memiliki hubungan untuk mempengaruhi kuantitas variabel motilitas spermatozoa semen, sehingga dapat mengindikasikan bahwa kuantitas kedua variabel ini juga adalah bebas untuk tidak saling bergantung satu dengan yang lain.

Perhitungan korelasi antara volume dengan gerakan massa spermatozoa semen ternak sapi (Tabel 2) adalah -0,29 pada ternak sapi yang dipelihara pada kandang tunggal dan -0,22 pada ternak sapi yang dipelihara pada kandang ganda. Angkaangka korelasi ini menunjukkan bahwa kuantitas variabel volume semen tidak juga memiliki hubungan untuk mempengaruhi kuantitas variabel gerakan massa spermatozoa semen, sehingga dapat mengindikasikan bahwa kuantitas kedua variabel ini juga adalah bebas untuk tidak saling bergantung satu dengan yang lain.

\footnotetext{
Korelasi Antara Motilitas dengan pH dan Gerakan Massa Spermatozoa Semen
}

Hasil analisis korelasi menunjukkan bahwa angka korelasi antara $\mathrm{pH}$ dengan mortalitas spermatozoa semen ternak sapi (Tabel 2) adalah 0,18 pada ternak sapi yang dipelihara pada kandang tunggal dan 0,05 pada ternak sapi yang dipelihara pada kandang ganda. Angka-angka korelasi ini menunjukkan bahwa kuantitas variabel $\mathrm{pH}$ semen tidak memiliki hubungan untuk mempengaruhi kuantitas variabel motilitas spermatozoa semen, sehingga dapat mengindikasikan bahwa kuantitas kedua variabel ini adalah bebas tidak saling bergantung satu dengan yang lain.

Analisis korelasi antara motilitas dengan gerakan massa menunjukkan bahwa angka korelasi antara mortalitas spermatozoa dengan gerakan massa spermatozoa semen ternak sapi (Tabel 2) adalah -0,21 pada ternak sapi yang dipelihara pada kandang tunggal dan juga -0,21 pada ternak sapi yang dipelihara pada kandang ganda. Angka-angka korelasi ini menunjukkan bahwa kuantitas motilitas spermatozoa semen tidak memiliki hubungan untuk mempengaruhi kuantitas variabel gerakan massa spermatozoa semen, sehingga dapat mengindikasikan bahwa kuantitas kedua variabel ini adalah bebas tidak saling bergantung satu dengan yang lain. 


\section{Korelasi Antara Gerakan Massa Dengan pH}

Perhitungan korelasi antara gerakan massa spermatozoa semen ternak sapi dengan pH semen (Tabel 2) adalah -0,14 pada ternak sapi yang dipelihara pada kandang tunggal dan juga - 0,14 pada ternak sapi yang dipelihara pada kandang ganda. Angka-angka korelasi ini menunjukkan bahwa kuantitas variabel $\mathrm{pH}$ semen tidak juga memiliki hubungan untuk mempengaruhi kuantitas variabel gerakan massa spermatozoa semen, sehingga dapat mengindikasikan bahwa kuantitas keduaa variabel ini juga adalah bebas untuk tidak saling bergantung satu dengan yang lain.

\section{KESIMPULAN}

Kualitas semen sapi limousin dan Simental yang dipelihara di kandang tunggal lebih baik jika dibanding dengan yang dipelihara di kandang ganda. Hubungan antara variabel reproduksi pejantan Limousin dan Simmental yang dipelihara pada kandang tunggal dan kandang ganda tidak berkorelasi antar variabel satu dengan variabel lain.

\section{DAFTAR PUSTAKA}

Aerens, C.D., M.N. Ihsan, dan N. Isnaini. 2012. Perbedaan Kuantitatif dan
Kualitatif Semen Segar Pada Berbagai Sapi Potong Malangang

Ariefin, A.P., R.T. Taswin, dan M.S. Dadang. 2013. Kualitas semen segar sapi simmental yang dikoleksi dengan interval yang berbeda di Balai Inseminasi Buatan Lembang. Journal Ilmiah Peternakan 1(3): 907-913.

Arifiantini, R. I, 2012.Teknik Koleksi Evaluasi dan Evaluasi Semen Pada Ternak IPB Pres. Bogor.

Bhakat, M., K. Thushar, K.G. Ashok, and A. Zamil. 2014. Effect of season on semen quality of crosbred (Karan Fries) Bulls. Adv. Anim. Vet. Sci. 2(11): 632-637.

Byrkit, D.R. 1987. Statistic today: A Comprehensive Introduction. The Benyamin/ Cumming Publishing Company, Inc. Menlo Park California.

Coulter, G.H., R.B. Cook, dan J.P. Kastelic. 1997. Efeects of dietary energy on scrotal surface temperatur, seminal quality and sperm production in young beef bulls. Journal Animals Science 75(6):1048-1052

Dewi, S.A., Y.S. Ondho, dan E. Kurnianto. 2012. Kualitas semen berdasarkan umur pada sapi Jawa. Animal Agriculture Journal 1(2): 126-133

Garner, D.L. dan E.S.E. Hafez. 2008. Spermatozoa and Seminal Plasma. in B. Hafes and E.S.E Hafez. Reproduction in Farm Animal $7^{\text {th }}$ ED. Lippinicot Wiliams and Wilkins Baltimore, Marryland, USA. Hal 503-524.

Hafez, E. S. E. 2008. Artificial Insemination. In Reproduction In Farm Animals. E. S. E Hafes 
(editor) $7^{\text {th }}$ edition. Lea and Febiger:376-390

Hafez, E. S. E. 2000. Semen Evaluaation in Reproducation in Farm Animals.7thn Edition Lippncott Williams and Wiklins Maryland USA.

Hartanti, D., E.T. Setiatin, dan Sutopo. 2012. Perbandingan penggunaan pengencer semen sitrat kuning telur terhadap persentase daya hidup spermatozoa sapi Jawa Brebes. Animal Agricultural Journal1(1): 33-42.

Khairi, F. 2016. Evaluasi reproduksi dan kualitas semen sapi simmental terhadap tingkat bobot badan berbeda. Jurnal Peternakan 13(2): 54-58.

Kiani, F.A., Y. Arfan, A.Z. Muhammad, N. Mudussar, Z. Akbar, U.R.S. Mujeeb, dan A.S. Magsi. 2014. Effect of age on physical characteristics of Kundhi buffalo bull semen. International. Journal of Current Mikrobiologi and Applied Sciences. 63(11): 445- 453

Kurnianto, E. 2010. Ilmu Pemuliaan Ternak. Lembaga Pengembangan dan Penjaminan Mutu Pendidikan. Universitas Diponegoro Semarang

Melita, D., Dasrul dan M. Adam. 2014. Pengaruh umur pejantan dan frekuensi ejakulasi terhadap kualitas spermatozoa Sapi Aceh. Jurnal Medika Veterinaria 8(1): 1519

Muada, D. B., U. Paputungan., J. H. Manopo dan S. H. Turangan. 2017. Karakteristik semen segar sapi bangsa Limousin dan Simmental di Balai Inseminasi Buatan Lembang. Jurnal Zootek 37(2): 360-369
Nyuwita, A., T. Susilawati, dan N. Isnaini. 2015. Kualitas semen segar begu sapi Simmental pada umur yang berbeda. Jurnal Tropika 16(1): 6168

Rahmawati, M.A., T. Susilawati, dan M.N. Ihsan. 2015. Kualitas semen dan produksi semen beku pada sapi dan bulan penampungan yang berbeda. Jurnal Ilmu-Ilmu Peternakan 25(3): 25-36.

Sarastina, T. Susilawati, dan G. Ciptadi. 2012. Analisa beberapa parameter motilitas spermatozoa pada berbagai bangsa sapi menggunakan computer assisted semen analysis (CASA). Journal Ternak Tropika 6(2):1-12.

Sugiarto, N., T. Susilawati, dan S. Wahyuningsi. 2014. Kualitas semen cair sapi Limousin selama pendinginan menggunakan pengencer CEP- dengan penambahan berbagai konsentrasi sari kedelai. Journal Ternak Tropika 15(1):51-57.

Suryana. 2009. Pengembangan usaha ternak sapi potong berorientasi agribisnis dengan pola kemitraan. Jurnal Litbang pertanian 28(1): 29-37.

Turyan, 2005. Penurunan Motilitas Spermatozoa Pada Berbagai Bangsa Sapi Akibat Proses Pembekuan. Skripsi. Fakultas Peternakan Universitas Brawijaya Malang.

Toelihere, M.R. 1993. Inseminasi Buatan Pada Ternak. Cetakan Ketiga Penerbit Angkasa Bandung. Hal: 92 -120 . 